\title{
Em literatura isso não é isso, mas aquilo
}

\author{
Juliana Cristina Salvadori *
}

\begin{abstract}
Resumo
Este artigo apresenta uma proposta de leitura do poema "Isso é aquilo", de Carlos Drummond de Andrade, experiência conjunta de leitores professor e alunos - a ser realizada em sala de aula, tanto por alunos do ensino fundamental e médio quanto por alunos da modalidade de Educação de Jovens e Adultos - EJA. O pressuposto básico é o de que o texto literário, pela sua especificidade de objeto estético, por um lado, no qual a questão da forma, do como, desempenha papel intrínseco na constituição do sentido, proporciona ao seu leitor, justamente pela mediação estética, uma experiência formativa, humanizadora no sentido que Antonio Candido confere a este termo em seus textos " $\mathrm{O}$ direito à literatura" e "A literatura e a formação do homem" . Por outro lado, também por ser um sistema semiótico-linguístico, o texto literário, sua multiplicidade de formas, temáticas, estratégias, acaba por prover ao leitor um repertório diversificado que o ampara e prepara a ler qualquer outro tipo de texto. Para isso, a metodologia proposta neste artigo, cheirando a truísmo, é o de que literatura só se aprende a ler justamente quando se lê literatura, especialmente no caso de um poeta com uma vasta produção metapoética como é o caso de Carlos Drummond de Andrade.
\end{abstract}

Palavras-chave: Estética. Humanismo. Poesia. Leitura. "Isso é aquilo".

Este artigo foi apresentado em mesa-coordenada composta pelos membros do grupo de pesquisa Estética e Humanismo, coordenado pelo professor Dr. Audemaro T. Goulart, mais especificamente no âmbito do projeto desenvolvido pelo grupo ao longo de 2011: "A educação estética do homem" (2002): o texto literário na formação humanística". ${ }^{1}$ O desafio que nos foi proposto era o de, a partir do poema "Isso é aquilo", de Carlos Drummond de Andrade, desenvolvermos nossas interpretações e pensarmos em modos de operacionalizá-las como propostas de leitura possíveis de serem levadas às

\footnotetext{
1 - Os demais artigos que compuseram a mesa foram: "O mito de evolução da linguagem no poema 'Isso é aquilo', de Carlos Drummond de Andrade", de Isabella Lígia Moraes; "Palavras são coisas: uma leitura de 'Isso é aquilo'”, de Luís Campos; "Leituras do poema 'Isso é Aquilo', de Carlos Drummond de Andrade", de Viviane de C. Maia Trindade.
}

* Universidade do Estado da Bahia - UNEB. 
salas de aula e desenvolvidas por professores do ensino fundamental, médio e/ou da Educação de Jovens e Adultos - EJA - em conjunto com seus alunos. O pressuposto básico é o de que a mediação estética, por meio desse objeto texto literário/poesia, objeto tido como de difícil interpretação, hermético, desempenha importante papel formativo para o que se entende como um indivíduo reflexivo e crítico. Como esclarece Candido em "A literatura e a formação do homem", é preciso pensar a literatura na escola de modo diferenciado, não simplesmente como casos exemplares, uma vez que

sua função educativa é muito mais complexa do que pressupõe o ponto de vista estritamente pedagógico. (...) A literatura pode formar; mas não segundo a pedagogia oficial, que costuma vê-la ideologicamente como um veículo da tríade famosa - o Verdadeiro, o Bom, o Belo, definidos conforme os interesses dos grupos dominantes, para reforço da sua concepção de vida. Longe de ser um apêndice de instrução moral e cívica (...), ela age com o impacto indiscriminado da própria vida e educa como ela - com altos e baixos, luzes e sombras. (CANDIDO, 2002, p. 83).

Nesse modo de pensar a literatura, o texto literário não pode servir de pré-texto a ilustrar algum ponto de vista moral e/ou ético. Não se pode apelar apenas para a sua função de narrativa organizadora das experiências humanas e selecionar quais experiências ou qual "modelo" de humanidade, se é possível dizer dessa forma, queremos apresentar aos alunos-leitores. Seu sentido humanizador está para além dessa narrativa de experiências, está na mediação estética das mesmas. Como conclui belamente Candido, a literatura "não corrompe nem edifica, portanto; mas trazendo livremente em si o que chamamos o bem e o que chamamos o mal, humaniza em sentido profundo porque faz viver." (CANDIDO, 2002, p. 85 - destaques nossos). A partir desse ponto de partida, este artigo apresentará uma proposta de leitura do poema de Drummond, já citado. Essa proposta, em camadas, concebe a leitura não como ato pontual, mas como processo contínuo que está sempre a rearranjar a interpretação de um repertório literário que se (con)forma de acordo com a própria experiência de ler.

O poeta Carlos Drummond de Andrade dispensa apresentação e vários de seus poemas integram o repertório de professores, estudantes e leitores em geral. A pecha de clássico e canônico não parece descabida nesse caso, visto a unanimidade que sua obra suscita na crítica e nos leitores em geral. Contudo, o poema "Isso é aquilo" permanece uma daquelas coisas 
assombrosas, um "ornitorrinco linguístico": dez estrofes enumeradas por algarismos romanos, cada uma dessas composta por dez "versos", se assim podemos chamá-los, que, em geral, contém pares "díspares", isto é, dois substantivos e os respectivos artigos definidos, como a estrofe abaixo:

\author{
VII \\ o dzeta o zeugma \\ o cemitério a marinha \\ a flor a canéfora \\ o pícnico o pícaro \\ o cesto o incesto \\ o cigarro a formicida \\ a aorta o Passeio Público \\ o mingau a migraine \\ o leste a leitura \\ a girafa a jitantáfora ${ }^{2}$
}

Penso que cada estrofe pode ser trabalhada por grupos de alunos como uma espécie de puzzle linguístico. Bem sabemos que há vários níveis de recepção de um texto literário e que nem todo texto encontra seu leitor ideal $/$ modelo logo de partida. Aliás, não é comum que esse leitor modelo já esteja configurada na primeira leitura uma vez que é pelo desdobramento da leitura que o sentido emerge, precário como a visão de Eurídice por Orfeu antes de esvanecer. Portanto, não há nada demais em ler despreocupadamente, ludicamente, como as crianças bem o sabem fazer. Ler não pelo sentido, não tentando descobrir o que o autor/texto diz, mas simplesmente acompanhando o jogo fonético/ óptico que o texto apresenta: ler pelo não sentido, o non sense, o escorregar de significante para significante em que curiosamente buscamos o padrão: aliterações? ecos? parentesco fonético/visual? Ler sabendo que isso nunca

2 Segundo o E-dicionário de termos literários, jitantáfora é um "termo sugerido por A. Reyes, na sua obra La experiencia literaria (1942), a partir de uma estrofe do escritor cubano Mariano Brull, para designar as composições de nonsense, (...). Estas composições não têm um significado controlado nem premeditado, mas apenas se concentram nos efeitos sonoros ou musicais que é possível extrair da poesia. Os poetas dadaístas primeiro, e os surrealistas e os concretistas depois, por exemplo, utilizaram muitas vezes este tipo de técnica para construir composições que resultam apenas pela força que é concedida ao significante, inventado ou reinventado, construído ou desconstruído. Não se confunde com a onomatopeia, porque esta imita sons reais e carece da inventividade própria da jitantáfora". Poeta como Drumond era, não há espaço em sua composição para o acaso. Em uma poesia como essa, uma jitantáfora, ao lado de uma girafa, tem muito de bestiário e pouco de experiência dadaísta ou surreal, ainda mais se pensarmos que logo na primeira linha ele cita outro "ser" que habita essa outra maneira de dizer das coisas, o zeugma, classificado como uma figura de linguagem que se dá por omissão. Essas talvez sejam indicações de uma dicção irônica no texto. Disponível em: $<$ http://www.edtl.com.pt/index.php?option=com mtree\&task=viewlink\&link_id=92\&Itemid $=2>$. 
poderia ser isso, mas sempre aquilo, o outro, significado sempre deferido/ diferido - ler no espaço que a différance abre.

Os demonstrativos são outra pista desse quebra-cabeças: matéria de discussões filosóficas e linguísticas desde aquele tempo mítico que chamamos de "desde os gregos" - desde Aristóteles, dizemos nós, quando queremos indicar desde sempre, desde o início - os pronomes são tidos como o limite no qual a linguagem não mais pode dizer, significar; não porque haja algo inefável no sentido, mas porque há um limite, um ponto até onde a linguagem vai, diz, mas que depois só pode mostrar, apontar: isso, aquilo, lá, ele. Algo que de tão conhecido não pode ser qualificado, predicado. $\mathrm{O}$ fenômeno da dêixis, aliás, é algo em que a linguística moderna presta muita atenção. Mas será preciso nomear tudo isso para esses leitores em um primeiro momento? Não são eles capazes de intuir esse limite da linguagem já exposto no próprio título e nos pronomes definidos que nada definem, na paradoxal inefabilidade desses substantivos concretos tão abstratos em nosso dia-a-dia?

Talvez essa seja uma leitura "inocente" demais, que desconsidera tanto a ironia presente nos artigos definidos que acompanham os substantivos - ironia, pois que de definidores tais artigos não tem nada, uma vez que os substantivos, pelo modo como se alternam em pares, sem um padrão bem definido, mesmo que "concretos", em oposição aos ditos abstratos, permanecem abstrações non sense, ainda mais quando a isso soma-se nosso desconhecimento quanto ao significado desses termos tão pouco usuais - quanto a ironia tão característica do próprio poeta. Mas essa leitura inocente, de primeiro momento, talvez seja menos inocente do que aquela empreendida pelo leitor desesperado, o leitororfeu, que afobadamente tenta olhar para Eurídice, o significado, sem saber que ele só pode se instituir no momento do canto apenas. Mas essa seria só a primeira parte do percurso de leitura. Há ainda mais, há demais, sempre sobra texto.

O poema termina com uma intrigante estrofe que, ao contrário das dez anteriores, não é enumerada por um numeral romano, mas sim pela letra F:

Forma

forma

forma 
a cor não pousa

no morto que a procura

$$
\begin{aligned}
& \text { nem a densidade habita } \\
& \text { nessa que antes de ser } \\
& \text { já neixou de ser não será } \\
& \text { mas é }
\end{aligned}
$$

forma
festa
fonte
flama
filme
não encontrar-te é nenhum desgosto
pois abarrotas o largo armazém do

factível

onde a realidade é maior do que a

realidade

Pela própria não enumeração, pela volta do verso-sentença (sujeito-verbopredicado), mesmo que disposto, tipograficamente, de modo tão irregular, essa estrofe nos diz que estamos agora mediante outro tipo de leitura, uma que nos demanda outra(s) estratégia(s). De fato, quando lida e comparada às demais estrofes, essa é a que se destaca como elemento "estranho", um outro poema dentro de um poema, uma poema-explicação. Como se o poeta decidisse em último momento nos presentear com uma chave de leitura: "Forma/ forma/ forma/ que se esquiva". A questão do tom, da dicção, volta à baila: esse vocativo tão significativo - Forma/ forma/ forma - em um poema em que não há, de fato, até o momento da estrofe $\mathrm{F}$, nada do que comumente entende-se como poema/texto a não ser a cuidadosa disposição de "versos" em "estrofes" tão conspicuamente distintas (numeradas) soa à ironia. Haveria algo que não a forma, que não os nomes das coisas, visto que nem cor nem densidade compõem um/o poema? Os demonstrativos, também, não apontam justamente para esse limite onde a linguagem, quiçá a poesia, não pode mais significar, ponto no qual não há realidade - densidade, cor - e nem linguagem, só o "isto", a forma, "que antes de ser / já / deixou de ser não será / mas é"? E o que dizer da dupla negativa em "e não encontrar-te é nenhum desgosto"?

Penso que esse seria o primeiro movimento da leitura em conjunto, o ir para o texto. Mas penso também que uma das maneiras de realmente se ler literatura, mais especificamente poesia na escola seja, de fato, lendo literatura, lendo poesia com os alunos, e não deixando para que cada um exerça/exacerbe 
sua "sensibilidade inata". Isso porque para se ensinar a ler literatura, se é que isso é possível de ser feito, como técnica (téchne e ars), um dos grandes temas, eu diria eixo, é o da arte reflexiva, a que fala de si mesma: metapoemas no caso da poesia. É preciso ler porque certos motivos / preocupações são recorrentes. $\mathrm{Na}$ literatura moderna (romântica, simbolista, parnasiana, modernista) essa questão da reflexão sobre o fazer artístico é central. É difícil, ao lermos algum escritor, não nos deparamos com poemas dizendo sobre fazer poemas. Drummond, por vezes tido como hermético, escreve uma poesia em grande medida metapoética. E essa seria outra proposta, ou uma segunda leitura, uma leitura em outra camada, do poema "Isso é aquilo". Ler esse poema de Drummond a partir da leitura de outros poemas de Drummond, poemas que falem do fazer poesia e do lugar dessa poesia, bem como do poeta, naquele mundo prosaico que ele habita.

"Procura da Poesia" (ANDRADE, 2002), por exemplo, é um desses poemas-sobre-poemas, poema-aula-de-poesia. Os versos "Penetra surdamente no reino das palavras./ Lá estão os poemas que esperam ser escritos" adquiriram tal força que habitam nosso repertório como se tivessem vida própria e independente do resto do poema - talvez resquício do nosso amor por aforismos e dísticos "pedagógicos", talvez porque seja justamente nesse ponto que o scriptor cessa de nos dizer o que não é poesia, o que não serve mais como poesia, todos aqueles conceitos e temas caducos (a morte e a vida "Não há criação nem morte perante a poesia"; os acontecimentos; os sentidos do corpo, os sentimentos - "O que pensas e sentes, isso ainda não é poesia"; a memória, a infância - "Não recomponhas tua sepultada e merencória infância"; enfim o que nos rodeia - "não tires poesia das coisas") e passa a dizer, de fato, não sobre "o quê" fazer poesia, mas o "como": "penetra surdamente", "tem paciência”, “espera”, "aceita-o”, "chega mais perto”. Esse poema-aulade-poesia, de fato, mostra-nos não só como escrever poesia, mas como lêla. A partir daí, podemos voltar ao poema "Isso é aquilo": o poema começa a se fazer quando escutamos as palavras, seu silêncio, e contemplamos suas multifaces, uma vez que o significado só pode emergir naquele ato paciente do ler, esse "isso" e esse "aquilo" só vem a ser - o que já não são mais, pois que o ato de dizer se dá sobre o que já foi - quando há o evento, a leitura, que é acontecimento irrepetível. O gesto pode ser repetido, o ler, mas não o evento aquele emergir do significado é tão fugaz quanto único. Há, no entanto, ainda realidade sobrando "no armazém do factível" e é por isso que a gente se propõe a ler, de novo, o poema, que será, a cada vez, não isso mas aquilo - outro 
a emergir. "Procura da poesia", "O lutador", "Poema de sete faces" podem, e acredito mesmo que devam, ser lidos em conjunto com "Isso é aquilo", não como chaves de resposta, não para nos poupar do assombro que "Isso é aquilo" produz, mas para vislumbrar outros possíveis/factíveis trajetos em meio ao nosso tateante percurso pelo "reino das palavras".

Em outra camada ainda, outra proposta na linha de ler poesia/literatura lendo poesia/literatura seria a de oferecer aos leitores um repertório de metapoemas, tarefa de fácil execução haja vista a grande preocupação dos escritores modernos em serem lidos, se não por seus contemporâneos pelo menos pela posteridade, a partir de sua própria concepção de arte e literatura, isto é, a partir do projeto literário que cada um tomou para si a responsabilidade de erigir. Essa seria uma proposta de leitura que poderia ter "Isso é aquilo" tanto como ponto de partida da reflexão sobre o "como" da poesia e da literatura quanto como ponto de chegada. Explico. Nossa habitual tendência para a ordem cronológica no estilo linha do tempo quase que imediatamente salta a organizar os textos nesta determinada ordem. Talvez essa seja, inicialmente, uma boa opção. Afinal, uma proposta de leitura com tal amplitude - cobrir vários autores, em vários períodos - demanda uma preocupação contextualizadora para evitar certas interpretações anacrônicas. Contudo, é preciso relativizar essa linha do tempo, sincronizar essa diacronia para que nem se caia, por um lado, naquela leitura teleológica - toda a poesia caminhou, evoluiu, até esse momento - nem, por outro, em uma rigidez estanque de rótulos redutores. Em outras palavras, ao se ler "comparativamente" é preciso ter em mente que poesia e literatura significam uma coisa para o parnasiano Olavo Bilac (a ourivesaria de "Profissão de fé") e outra totalmente diferente para o nosso Drummond de "Isso é aquilo", por certo. Mas é preciso ainda ter em mente que o Drummond de A rosa do povo (2002) não é o mesmo de Claro enigma (2002), por exemplo, e que simbolistas como Cruz e Souza e Pedro Kilkerry também têm suas diferenças apesar de, a princípio, serem rotulados como pertencentes ao mesmo estilo/escola. Isso porque "o que é fazer literatura/ poesia" e "qual é o papel/lugar do poeta" são questões históricas: cada poeta, em cada poema, oferece uma resposta diferente, ou várias respostas, como Paulo Leminski bem condensa em seu poema-definição(ões) "Limites ao léu":

Limites ao léu

POESIA: "words set to music" (Dante

via Pound), "uma viagem ao

desconhecido" (Maiakóvski), "cernes

e medulas" (Ezra Pound), "a fala do 


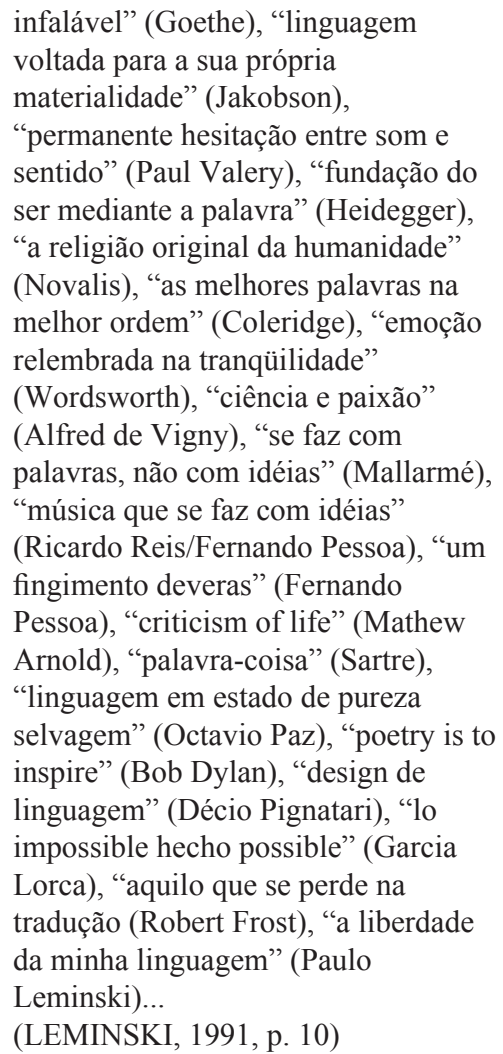

Nenhuma dessas respostas é necessariamente a correta ou a melhor. Não se sai de Dante para chegar em Leminski como se estivéssemos cumprindo etapas de um processo evolutivo. A leitura, a literatura, não se dá em ordem, mas em saltos. Por isso, acredito, "Isso é aquilo" pode e deve ser tanto ponto de partida quanto de chegada - de onde se sai e para onde se volta, continuamente, sabendo que não se volta nunca ao ponto original: aquela primeira leitura, a inicial, não é mais possível: não há círculo hermenêutico, há a espiral. Voltase ao texto, àquela concepção do fazer poesia, mas a partir de outro ponto de vista, (con)formado a partir de outras experiências. Penso que a proposta de trabalhar com poesia em sala de aula, um gênero por si só considerado por muitos inacessível enquanto, para outros, gênero acessível somente aos poucos escolhidos, vem ao encontro de poema tão "exemplar", no que tange essa tal inacessibilidade e/ou inefabilidade do sentido. Não porque a literatura e/ou poesia sejam, apenas, essa "fala do infalável”, mas porque, de certo modo, elas nos demandam aprender e empreender o exercício da leitura pelo não-sentido, 
a estabelecer outra relação com um texto que, em seu movimento inicial, estabeleceu também, por si, outra relação com seu objeto, desde o início um não-objeto:

Não se deve esperar uma simples confrontação de palavras para ter a prova de que, pela poesia, nós sejamos orientados para uma outra relação que não seria de potência, nem de compreensão, nem mesmo de revelação, relação com o obscuro e o desconhecido. Pressentimos até que a linguagem, seja a literária, a poesia, seja ela verdadeira, não tem como função trazer à luz, à firmeza de uma palavra, que nomeia aquilo que se afirmaria, informulado, nesta relação sem relação. A poesia não está aí para dizer a impossibilidade: ela lhe responde somente, respondendo ela diz. Assim, em nós, é a partilha secreta de toda palavra essencial: nomeando o possível, respondendo ao impossível. (BLANCHOT, 2001, p. 93).

\begin{abstract}
This essay aims at presenting a tentative reading proposal of Carlos Drummond de Andrade's poem "Isso é aquilo". It proposes the experience of teacher(s) and students - be it young or adult students - reading literature together in the classroom. The underlying assumption rests on the notion that a literary text, due to its specificity as an aesthetic object, on the one hand - an object in which the aesthetic form, the issue of "how", plays a constitutive role in terms of meaning - provides its reader, due to the aesthetic mediation, a formative experience, a humanizing one in the sense Antonio Candido confers to this concept in his essays "O direito à literatura" and "A literatura e a formação do homem". On the other hand, the literary text is a text, i.e., it is part of a linguisticsemiotic system, and because of the multiplicity of its forms, themes, and strategies, it can provide its readers with a varied repertoire, which enables him/her to read any other kind of text.
\end{abstract}

Keywords: Aesthetics; Humanism; Poetry; Reading; "Isso é aquilo".

\title{
Referências
}

ANDRADE, Carlos Drummond de. Reunião: 10 livros de poesia. 7. ed. Rio de Janeiro: J. Olympio, 1976. 280p. 
ANDRADE, C. D. Claro Enigma. In: ANDRADE, C. D. Obra completa. Rio de Janeiro: Nova Aguilar, 2002.

ANDRADE, Carlos Drummond de. A rosa do povo. São Paulo: Companhia das Letras, 2012.

BLANCHOT, Maurice. A questão mais profunda. In.: A conversa infinita; a palavra plural. São Paulo: Escuta, 2001, p.41-61.

CANDIDO, Antônio. A literatura e a formação do homem. In.: Textos de intervenção. São Paulo: Duas Cidades, Editora 34, 2002.

CANDIDO, Antonio. O direito à literatura. In: Vários escritos. 3. ed. São Paulo: Duas Cidades, 1995.

CEIA, CARLOS. Jitantáfora. In: E-dicionário de termos literários. Disponível em: < http://www.edtl.com.pt/index.php?option=com mtree\&task=viewlink\&link_id=92\&Itemid=2>. Acesso em 10 out. 2010.

LEMINSKI, Paulo. Agora é que são elas. São Paulo: Brasiliense, 1991. 